بمث رقم (ع)

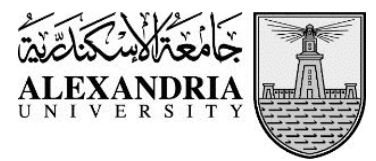

Pharos University

Faculty of Arts and Design

Interior design and Furniture

\title{
The Potential of Origami Concept In the Forming of the Theatrical Costumes Design
}

Randa Ismail Taha Abdel Mageed Negm 


\section{Assistant Prof., Department of Decoration \\ Faculty of Fine Arts, Alexandria University, Egypt \\ Secondment in Pharose University \\ Email.rihran@gmail.com}

\section{Importance of the study:}

The importance of this study lies in the following matters:

The research will contribute to the enrichment of theatrical design and open up new horizons for the creative design of complex costumes inspired by the origami theory.

\section{Objectives of the study:}

The objectives of this study are as follows:

○ To open up the prospects for designers in theatrical costumes design and endless possibilities in the theatrical costumes design inspired from the origami theory.

○ To draw attention to the abilities of origami theory, this can be used in the forming of theatrical costumes.

\section{Problem of the study:}

This study attempts to answer the following questions:

$\circ$ Can we employ complex theatrical costumes using origami theory in the costumes design?

o Can we benefit from origami theory to enrich the visual language of the theatrical costumes? 


\section{Hypotheses:}

Through this research, the researcher expects to reach the following results:

- To illustrate the ability of origami theory to enrich the costumes.

o To suggest ways in which costumes designers can take advantage of origami theory in order to enrich visual vocabulary in theatrical costumes design.

\section{Research Methodology:} through:

The methodology of the research is an analytical deductive approach

O An analysis of different forms that have benefited from origami theory in industry and architecture.

o A deductive study of ways to benefit from origami concept in theatrical costumes, followed by a proposal by the researcher to use origami theory in theatrical costumes designs.

\section{Abstract:}

Origami concept is one of the biggest trends of design in the world for the past few years, Origami is not only a sophisticated art form, but it inspires innovative concepts in design and inventions in engineering, architecture, and technology. Also this art of paper folding has greatly influenced artists and designers from fashion to interior design, inspiring numerous origami style products and spaces. ${ }^{27}$

The paper proposes an approach where theatrical costumes design can be developed according to the origami concept. Costumes designers can take advantages of the complex origami concept, by the use of folded fabric techniques and computer technology, where algorithms of mathematical and geometric patterns can produce new designs and forms of costumes design. This will opens up new horizons in costumes design inspired from origami concept in the formation of the theatrical costumes design. 
Designers can set up their costumes design inspired from geometric patterns, fold, and creases, especially in the futuristic, fantasy, abstract and alien performances. This will enhance the visual visions of costumes designers, and will allow endless possibilities and an infinity creative formation. By changing the steps in the folding process, the costume designer will end up with a totally different costumes design.

\section{Keywords:}

Costumes design, origami theory, Kirigami, Modular origami, Wet-folding.

\section{Introduction:}

"The process of creating a complex pattern and the rich variety that may be obtained from a sequence of very simple operations are close to the spiritual and the molecular basis of life" ${ }^{28}$.

origami artist and theorist

$$
\text { Peter } \text { Engel }^{29} \text { - an }
$$

One of the biggest trends in the design world for the past few years has definitely been the origami. ${ }^{30}$ Over the last few decades, origami has evolved from an art form into a scientific discipline, where folding techniques have been widely applied to fields of engineering, architecture, and design, made possible in large part by methods for the mathematical analysis of folded surfaces. ${ }^{31}$ This ancient art of paper folding has greatly influenced artists and designers from fashion to jewellery, inspiring numerous origami style products and spaces.

"Much of the charm of origami lies in its simplicity: There is the square, there are the folds".

28 - http://origamiquotes.tumblr.com/

29 - Peter Engel is an American origami artist and theorist, science writer, graphic designer, and architect. He has written several books on Origami.

30 - http://www.designandpaper.com/?p=2411

31 - https://www.seas.harvard.edu/softmat/downloads/2012-20.pdf 
Robert Lang

Folding a sheet of paper along a form can lead to structures seen in decorative art and forms.

\section{Origami Art Origins}

Although origami is nowadays synonymous with Japan, the first recorded reference to it comes from China, where paper was first produced around $200 \mathrm{AD}$ as a cheap alternative to silk. The art of Chinese paper folding was brought with paper to Japan in the 6th century by Chinese Buddhist monks. ${ }^{32}$

'Origami' is a Japanese word, which combines the verb 'oru' to fold, and the noun 'kami' paper. Quoting from Merriam Webster's Third New International Dictionary, origami means: The art of Japanese paper folding. , Something as a representative made by origami. ${ }^{33}$

The term origami, coined from the words oru (to fold) and kami (paper), is first mentioned during the 4th century A.D in Japan. It referred to square and rectangular pieces of paper, folded into symbolic representations of the spirit of God, and hung at the Kotai Jingu (Grand Imperial Shrines) of Ise as objects of worship. During the 11th century A.D. folded paper came to be used for certificates that accompanied valued objects such as swords or gifts presented to others. At this time, the term "origami" referred to the documents, whereas the term origami tsuki, "accompanied by origami", meant that a gift was accompanied by a certificate. This certificate had the same meaning as the word diploma, which in ancient Greek also means "a letter folded in two." ${ }^{34}$ The use of the term origami for recreational paper folding did not appear until the end of the nineteenth century or the beginning of the twentieth.

32 - https://plus.maths.org/content/power-origami

33 - Nergiz YiĞiT , Industrial Product Design by Using Two-Dimensional Material in the Context of Origamic Structure and Integrity, 2004 (http://citeseerx.ist.psu.edu/viewdoc/summary?doi=10.1.1.427.3923)

34 - Katherine A. Liapi , Transformable Architecture Inspired by the Origami Art: Computer Visualization as a Tool for Form Exploration, http://cumincad.scix.net/data/works/att/6cde.content.pdf 35 - Katherine A. Liapi , Transformable Architecture Inspired by the Origami Art: Computer Visualization as a Tool for Form Exploration, http://cumincad.scix.net/data/works/att/6cde.content.pdf 
In 1927 the earliest known reference of curved-crease sculpture is from a student's work at the Bauhaus, from a preliminary course in paper study taught by Josef Albert. 36He teaching Origami at the Bauhaus, Paper folding was a tool to experience construction, Working hands-on, learning by doing. "The student had to solve it entirely independently. No technical explanations were given." . 37 Albers points out that working with materials and exploiting its properties for a design leads to a fundamental understanding of efficiency of means, material will be utilized to its maximum potential, which leads to light design proposals with little waste. Lastly designing curved crease models provides students with unexpected revelations, which was a pedagogical value that Albers appreciated ${ }^{38}$

In the 1930s, the art of origami expanded beyond traditional designs. At the same time, the development of instructions, based on line systems and arrows, made origami available to the west as a new creative tool. After this time, experimentation with new ideas went beyond figural origami to gradually include more abstract forms, among them various types of closed and open surface developments, which can also find applications in transformable architecture.

The modern art form was reborn in the early 20th century through the efforts of a Japanese artist, Akira Yoshizawa, who created new figures of artistic beauty and developed a written instructional language. "Creative" origami caught on worldwide in the 1950s and 1960s. Beginning in the 1970s, many geometric design techniques were developed that enabled the creation of figures of undreamed-of complexity .The mathematical theory of origami was greatly expanded in the 1990 s, leading to computer-aided origami design. (fig. .1) 40

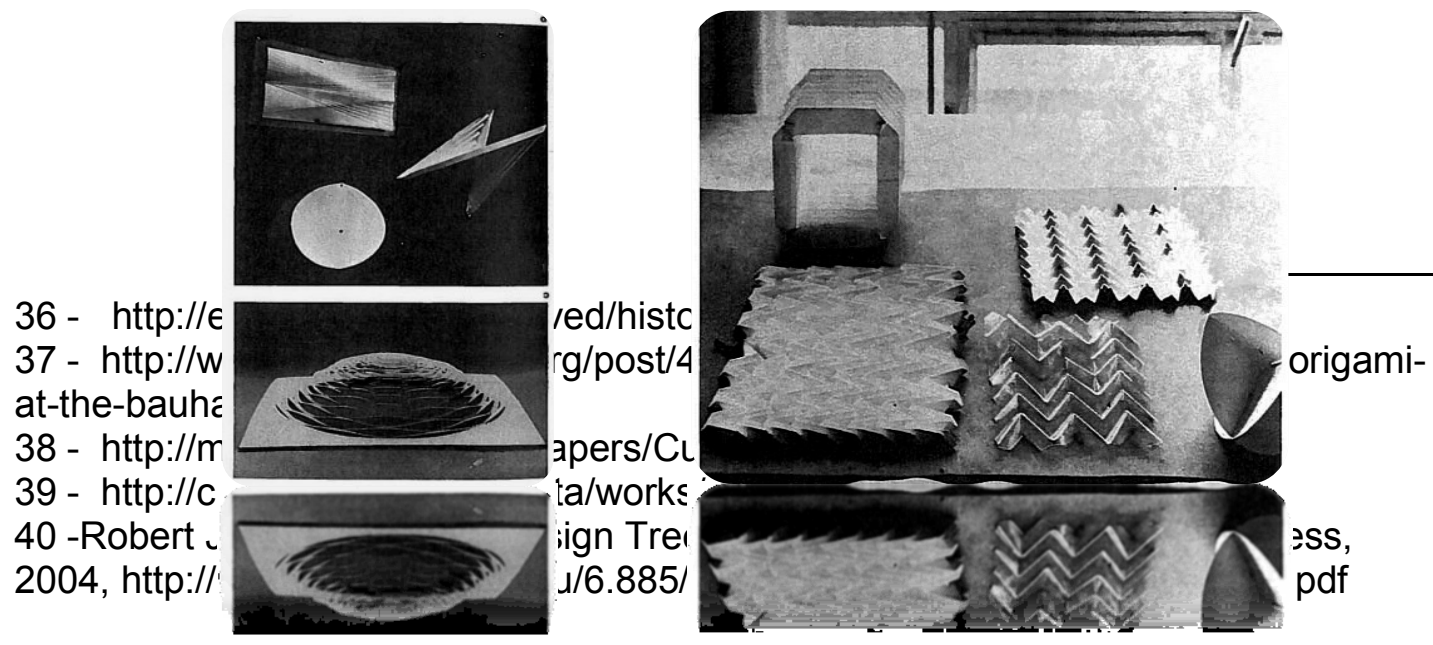


(fig .1 )Some of the origami forms made by Bauhaus students .

Michael Lafosse in his book( Advanced Origami, an artist's guide to performance in paper) says:"Origami is engineering and every piece of origami represents a puzzle to those who have never seen anything like it before. Because of this, viewers ask, "How was this done?" But some origami sculptures manage to go beyond this surface reaction to convey a deeper message to the viewer". 41

Several styles of origami are represented in Folding Paper, as diverse as the artists' imaginations and as dynamic as the paper from which it is crafted. ${ }^{42}$ There are two main types of geometric origami : modular origami and origami tessellations, also there are some types of origami such as Wet-folding, cranes and Kirigami

\section{Modular origami}

Modular origami or unit origami is a paper folding technique which uses two or more sheets of paper to create a larger and more complex structure than would not be possible using single piece origami techniques. Each individual sheet of paper is folded into a module, or unit, and then modules are assembled into an integrated flat shape or three-dimensional structure by inserting flaps into pockets created by the folding process. These insertions create tension or friction that holds the model together. ${ }^{43 *}$

\section{Cranes}

- Michael Lafosse, Advanced Origami, an artist's guide to performance in paper, Tuttle « publishing, http://www.enryo.ro/carti/origami\%20advanced.pdf

- http://www.lywam.org/wp-content/uploads/2014/02/Origami-Pre-Visit-Materials.pdf $\leqslant r$ - https://en.wikipedia.org/wiki/Modular_origami $\leqslant r$ 
The term refers to an origami technique whereby one folds multiple cranes from a single sheet of paper (usually square), employing a number of strategic cuts to form a mosaic of semi-detached smaller squares from the original large square paper. The resulting cranes are attached to one another or at the tip of the body. The trick is to fold all the cranes without breaking the small paper bridges that attach them to one another or, in some cases, to effectively conceal extra paper. ${ }^{44}$

\section{Kirigami}

Kirigami is a variation of origami that includes cutting of the paper (from Japanese "kiru" = to cut, "kami" = paper), rather than solely folding the paper as is the case with origami, kirigami starts with a folded base, which is then cut; cuts are then opened and flattened to make the finished kirigami. Kirigami are usually symmetrical, such as snowflakes, pentagrams, or orchid blossoms. $^{45}$ (fig .2)

also there is another type of origami like Origami Tessellation ${ }^{46}$ and Wet-folding ${ }^{47}$.

- a pattern fills a pli

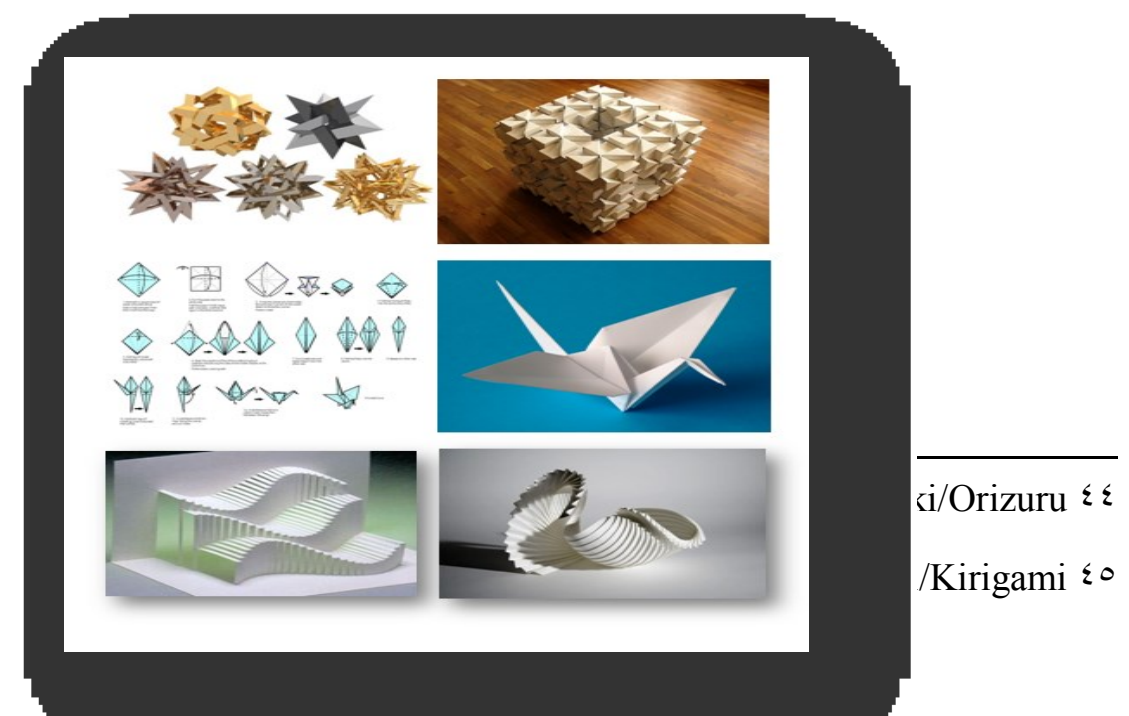
using pleats to connect elements such as twist folds in a repeating fashion. Many origami tessellations have the appearance of woven paper. http://www.lywam.org/wpcontent/uploads/2014/02/Origami-Pre-Visit-Materials.pdf

- Wet-folding is an origami technique, involving the dampening of thick papers in order $\leqslant \vee$ to make them more foldable and create sturdier models. https://en.wikipedia.org/wiki/Modular_origami 


\section{Origami Applications:}

"The intrigue of origami is found in its endless possibilities, limited only by your mind." 48

\section{Michael Lafosse}

Origami has been a source of inspiration for various domains such as interior and product design. The strong angular shapes and forms can be seen on products ranging from wallpapers to vases and the classic of the design world. The style of origami is also quite popular in furniture design, architecture and fashion.

\section{Origami Architecture:}

Architecture is one of the fields inspired by the origami theory. Some of the most challenging architectural designs are inspired by this Japanese art ${ }^{50}$. Great architects and designers have captured in their work the essence of geometry by using complex shapes and a great deal of imagination. ${ }^{51}$ (fig .3)

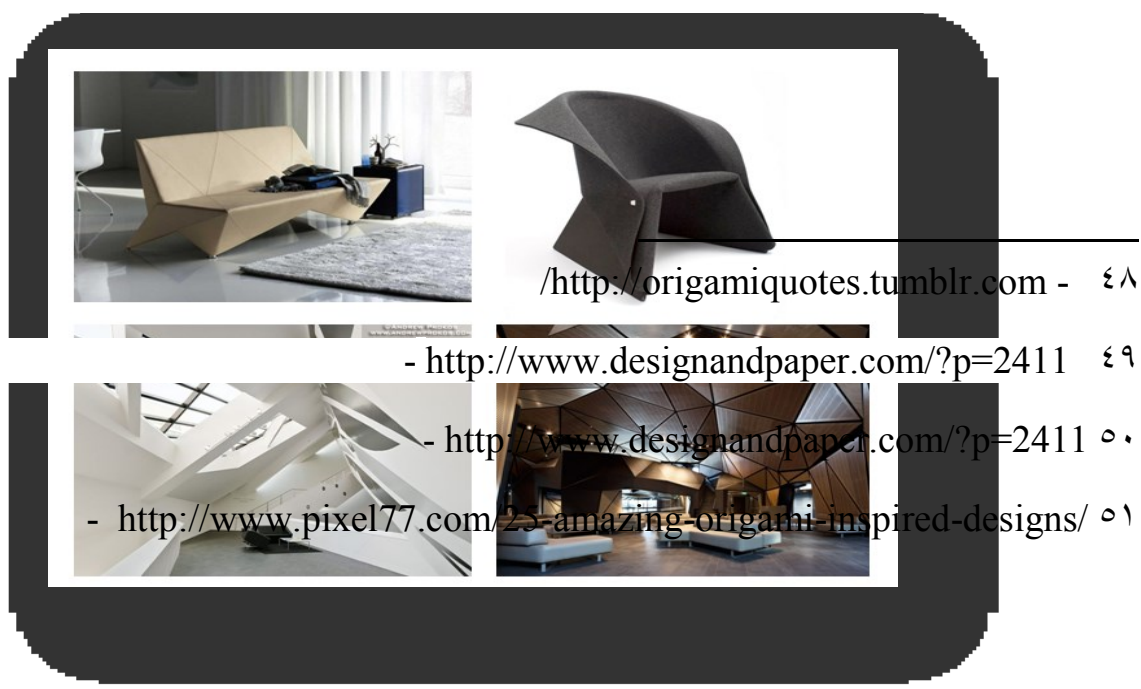


(fig.3 ) above origami furniture in the left and bottom origami architecture.

\section{origami fashion:}

Richard Alexander in his book (Origami Art) says: "The viewer needs time and space to absorb the beauty of an exquisite piece of origami art". ${ }^{52}$

With fashion constantly changing within a blink of an eye nobody can know what style or technique may be the next big hit. ${ }^{53}$

Nowadays, fashion designers use Origami theory into their creations. Origami is often associated with paper and fabrics sculptures. ${ }^{54}$ (fig 4)

\section{The Inspiration From The origami theory in the Forming of} The

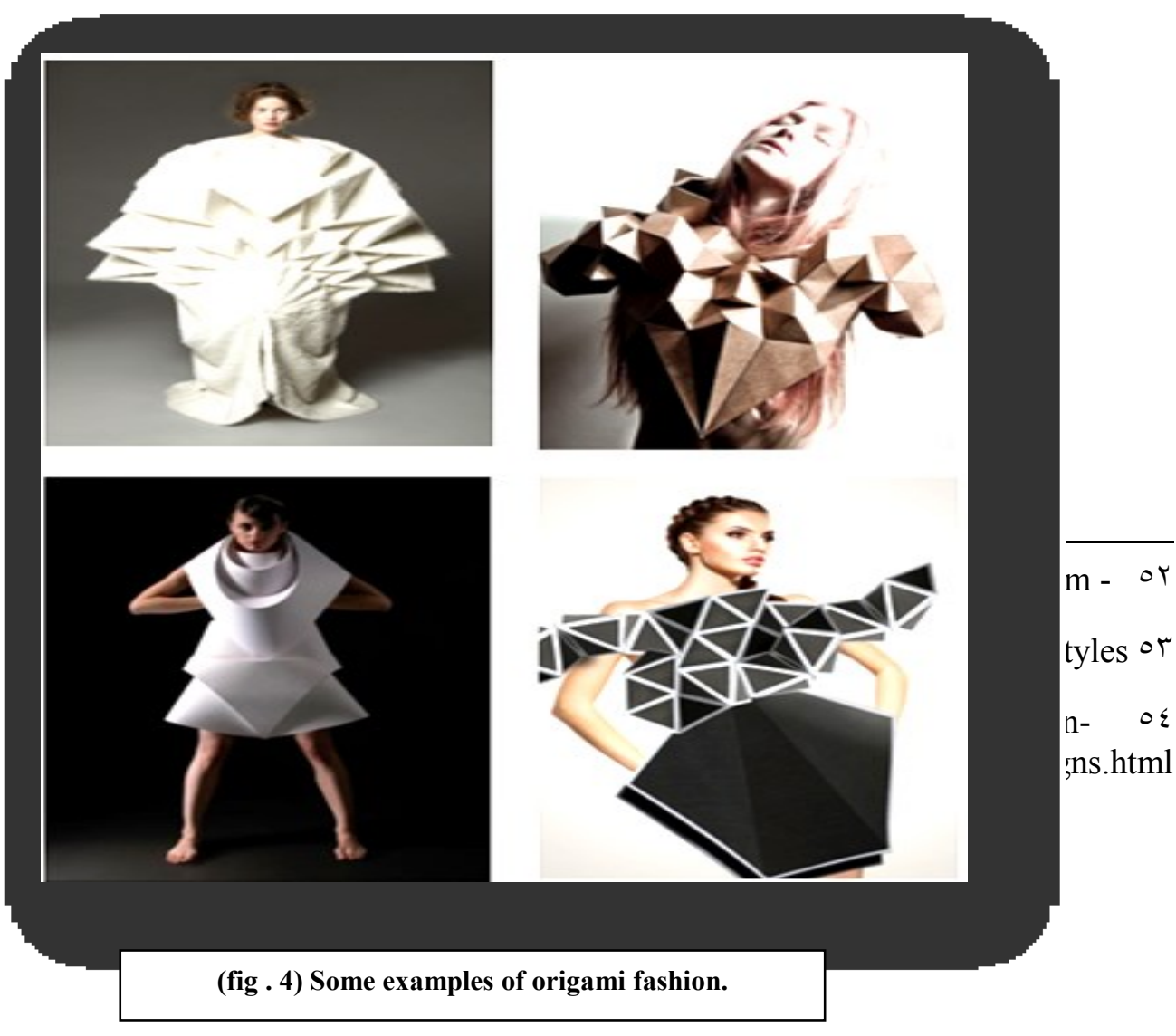




\section{Theatrical Costumes :}

Michael LaFosse in his book (Paper Art: the art of sculpting with paper) says: The appeal of folded paper is simple and innate: a play of surface texture, light, and shadow a tangible poetry.

To clarify the various possibilities of origami concepts in the formation of the theatrical costumes design; the following figures represent the proposed designs by the researcher showing the possibilities of the theatrical costumes design inspired from origami theory. It can create a full design of origami forms and shapes.

\section{Illustrations of the proposed researcher:}

"Design is all about building coherence between your constraints, your values, and your possibilities". ${ }^{55}$

Robert Lang, Designer Ayse Birsel ${ }^{56}$

Origami theory folding is the inspiration for the theatrical costumes forms. The major endeavor was to explore the relationship between the organic human forms of the theatrical actors and the geometric costume form created by the origami folds. During this process, the researcher experimented with different designs. The researcher tries to design an innovative and creative costumes inspired from origami theory.

Robert Lang ${ }^{57}$ says: "Origami is, first and foremost, an art form, an expression of creativity, and it is the nature of creativity that it cannot be taught directly. It can, however, be developed through example and practice". ${ }^{58}$

$$
\text { /http://origamiquotes.tumblr.com } 00_{-}
$$

(http://www.aysebirsel.com/) - Designer, Creative Director, Teacher, Speaker or

who is physicist American is an [citation needed](born May 4, 1961) -Robert J. Lang ov artists and theorists in the world. He is known for his origami also one of the foremost complex and elegant designs, most notably of insects and animals. He has studied and used computers to study the theories behind origami. He has themathematics of origami made great advances in making real-world applications of origami to engineering problems(https://en.wikipedia.org/wiki/Robert_J._Lang). 
The following illustrations by the researcher clarify the various design possibilities of costumes design inspired from origami theory.

\section{Scene I:}

"I find it fascinating that by changing the steps in the folding process you end up with a totally different model, so in essence, a square of paper has inside of it all the possibilities to be anything you can imagine". ${ }^{59}$

Gonzalo Garcia Calvo ${ }^{60}$

The first design is an integration between three-dimensional sculptural form and the actor. Origami paper folding is the main inspiration for this design concept . the creases of the fabric catch every play of light.

The design inspired by origami theory uses the aspects of origami such as folding, consists of three geometric pieces creasing and building of the structures out of geometric shapes and patterns (Fig. 5 )

\section{Scene II:}

"The intrigue of origami is found in its endless possibilities, limited only by your mind".

\section{Lafosse $^{61}$}

Michael

The second design inspired from origami theory, It consists of some of geometric pieces, with folded and creases parts .The idea was to emphasize simple, succinct shapes that embody simplicity. The designs have sharp lines

/http://origamiquotes.tumblr.com - 09

- An artist based in Madrid, Spain 7.

has been an origami artist for over 40 years, and is considered a - Michael G. LaFosse 7 ) leading authority and master of the art. An avid teacher, LaFosse co-founded the Origamido Studio, a learning center and design studio dedicated to the art of origami, and the only place in the world specializing in hand papermaking for the origami artist. Author of many books and videotapes relating to paperfolding and hand papermaking, LaFosse produces fine paper art and commercial designs for a variety of international clients 
with structural details: feminine but strong, lots of opposites, and strength in diversity. (Fig.6)

\section{Scene III:}

Kunihiko Kasahara ${ }^{62}$ says in his book (Amazing Origami) :"Origami creates the perfect union of esthetics and geometry, feelings and reasoning" .

The third design is consists of main four geometric pieces, with folded and creases parts .The costume design bring together elements of modern styles with futuristic looks. Origami paper folding is the main inspiration for this design concept. The design is the integration between three-dimensional costume design and the performer. Different designs, folds, and creases represent different expressions of characters of the performances (Fig. 7 ).

The previous costumes designs have completely unique patterns that are much more complex than the traditional pattern and have a more origamiinspired look to them. Using these patterns, creating a prismatic effect, it is possible to use fabrics for designs are created by uniting the advanced technology of permanently pleated polyester with the traditional form of paper lanterns, Fabric requires hot iron pressing and sewing techniques to create and retain the folds, while paper requires no supportive material or special techniques simply hand folding. ${ }^{63}$

\section{Conclusion:}

In the end, it can be pointed out that the origami theory and its techniques have great impact on costume design by enabling costumes designers to develop and achieve their complex and futuristic visions and to express the visual language of their own clearly and effectively. The costume design is the integration between three-dimensional sculptural form of costume design

62 - Kunihiko Kasahara :is a Japanese origami master. He has made more than a hundred origami models, from simple lion masks to complex modular origami ,such as a small stellated dodecahedron .He does not specialize in what is known as "super complex origami", but rather he likes making simple, elegant animals, and modular designs such as polyhedra ,as well as exploring the mathematics and geometry of origami. A book expressing both approaches is Origami for the Connoisseur) Kasahara and Takahama), which gathers modern innovations in polyhedral construction, featuring moderately difficult but accessible methods for producing thePlatonic solids from single sheets, and much more.

- https://digital.library.unt.edu/ark:/67531/metadc4277/m2/1/high_res_d/problieu.pdf ז 
and the performer. Different designs, folds, and creases represent different expressions of characters of the performances the inspiration from origami theory has a lot of advantages because of the infinite possibilities in the creating of theatrical costumes designs depending on the thoughts and visions of the designers to express the theatrical characters. new form of theatrical costumes inspired from origami concept can create a hybrid designs balance between the rational, physical design on one side and the irrational, metaphysical and natural design on the other side according to costume designers visions. by changing the steps in the folding process, the costume designer will end up with a totally different costumes designs .

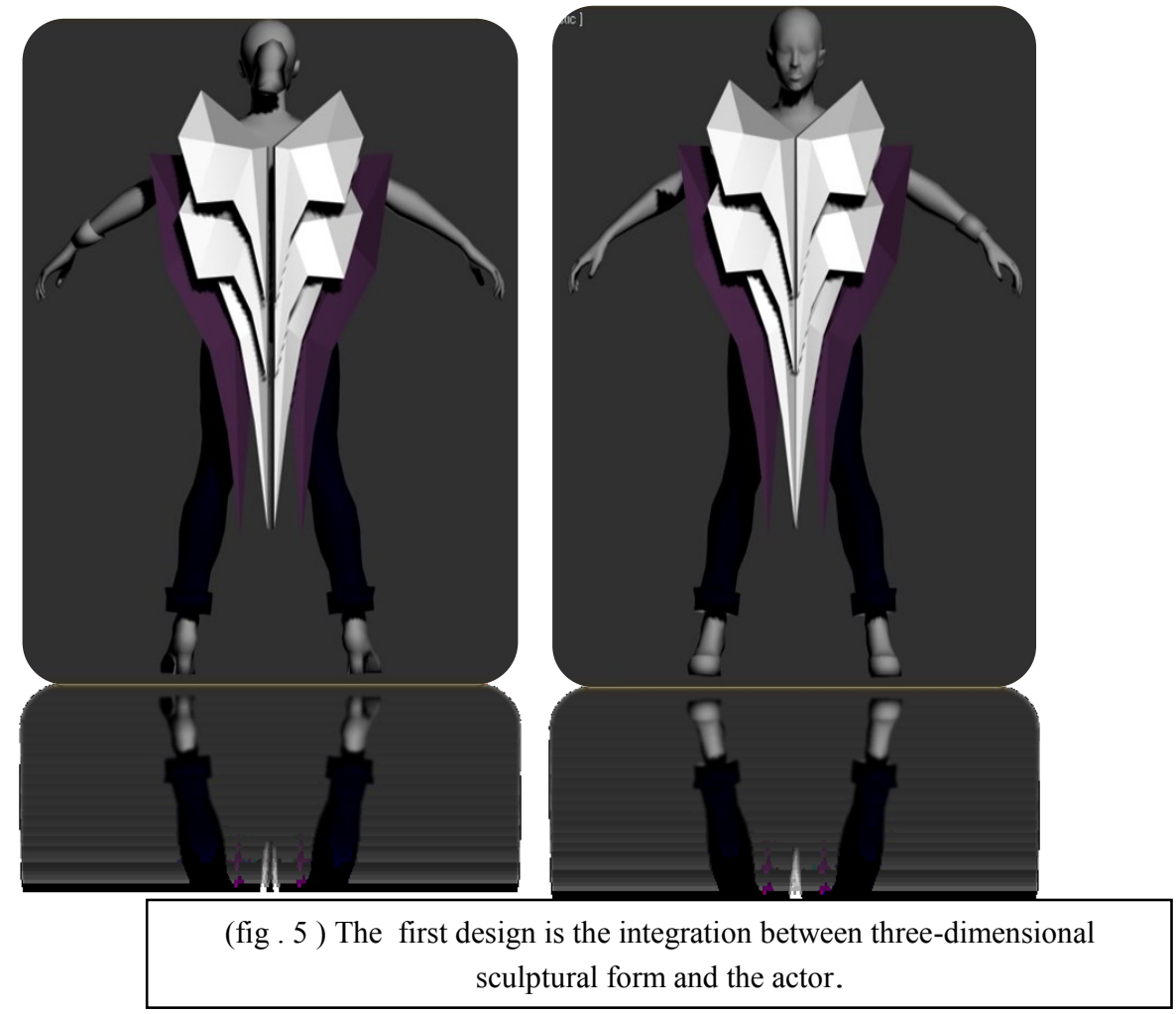




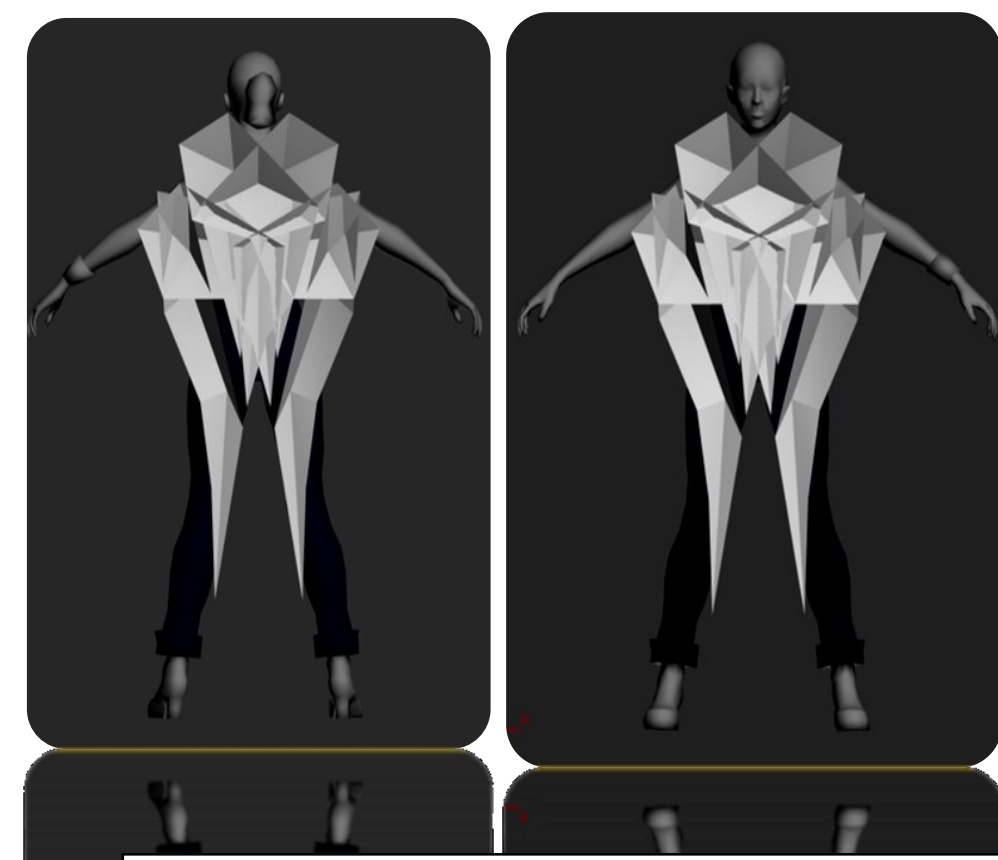

(fig .6 )The second design inspired by origami theory, It consists of two geometric pieces, with folded and creases parts .

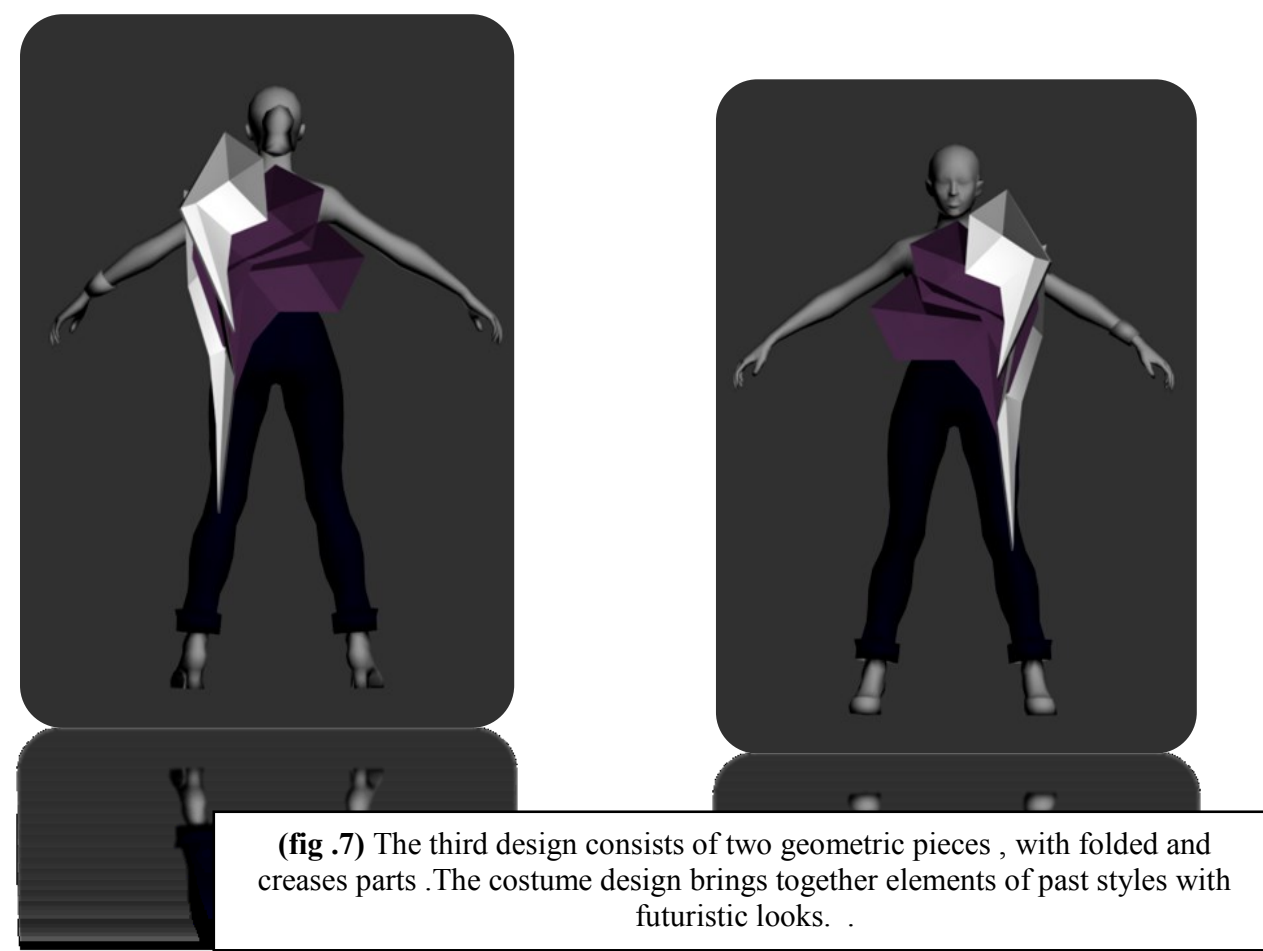




\section{References:}

- Erik D. DEMAINE and others, Curved Crease Folding a Review on Art, Design and Mathematics, http://martindemaine.org/papers/CurvedCrease_IASS2011/paper.pdf

- Katherine A. Liapi, Transformable Architecture Inspired by the Origami Art: Computer Visualization as a Tool for Form Exploration, http://cumincad.scix.net/data/works/att/6cde.content.pdf

- Michael Lafosse, Advanced Origami, an artist's guide to performance in paper, Tuttle publishing, http://www.enryo.ro/carti/origami\%20advanced.pdf

- Nergiz YİĞİT , 2004 , Industrial Product Design by Using TwoDimensional Material in the Context of Origamic Structure and Integrity, (http://citeseerx.ist.psu.edu/viewdoc/summary?doi=10.1.1.427.3923)

- Robert J. Lang, 2004, Origami Design Tree Theory for Uniaxial Bases, MIT press, http://courses.csail.mit.edu/6.885/fall04/erik_notes/anydpi/L18_slides. pdf

- Erik D. DEMAINE and others, Curved Crease Folding : a Review on Art, Design and Mathematics

,http://martindemaine.org/papers/CurvedCrease_IASS2011/paper.pdf

\section{Web sites:}

- http://www.sacramento365.com/event/detail/441730772/Folding_Pape r_The_Infinite_Possibilities_of_Origami

- http://origamiquotes.tumblr.com/

- https://www.seas.harvard.edu/softmat/downloads/2012-20.pdf

- $h t t p: / / w w w . d e s i g n a n d p a p e r . c o m / ? p=2411$

- https://plus.maths.org/content/power-origami

- https://en.wikipedia.org/wiki/Modular_origami

- https://en.wikipedia.org/wiki/Orizuru

- https://en.wikipedia.org/wiki/Kirigami

- http://www.pixel77.com/25-amazing-origami-inspired-designs/

- $\mathrm{http}: / / \mathrm{www} \cdot$ designandpaper.com/?p=2411

- http://origamiquotes.tumblr.com/

- http://www.trendhunter.com/slideshow/origamiinspired-fashion-styles 
- http://ajurettemagablog.blogspot.com.eg/2010/11/origami-inspiredfashion-designs.html

- http://origamiquotes.tumblr.com/

- http://erikdemaine.org/curved/history/

- http://www.design-is-fine.org/post/45030957361/josef-albers-teachingorigami-at-the-bauhaus 


\section{إمكانيات مفهوم الاوريجامي في تتكيل تصميم الازياء المسرحية}

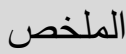

مفهوم الأوريجامي أو فن "طى الورق "هو واحد من اكبر اتجاهات التصميم في العالم على مدى

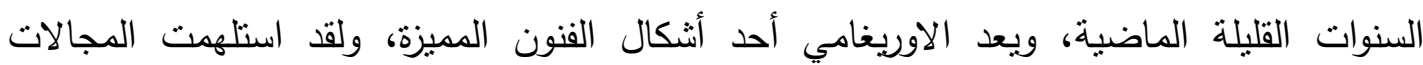

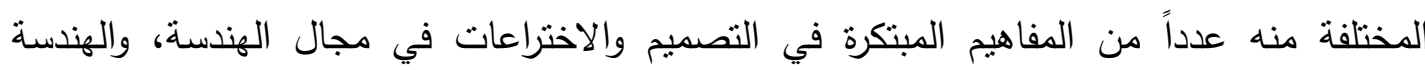
المعمارية، والتكنولوجيا كما أثر فن طي الورق على الفنانين والمصممين من الأزياء إلى التصميم

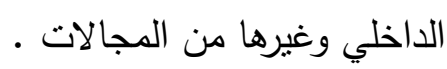

تقام الورقة البحثية مقترحاً عن امكانية الاستفادة من مفهوم فن الأوريجامى وأثنكاله المعقدة فى

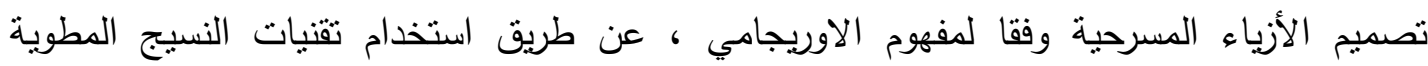
وتكنولوجيا الحاسوب، لتصميم أشكال و أزياء مسرحية. والاستلهام من مفهوم الأوريجامى يفتح آفاقاً جديدة في تصميم الأزياء المستوحاة من مفهوم الاوريجامي في تتكيل تصميم الأزياء المسرحية.

يمكن لمصمي الأزياء المسرحية تصميم أزياء مستوحاة من الأشكال الهندية لتراكيب

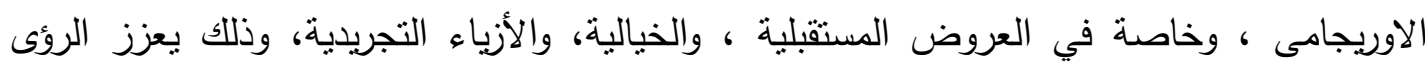

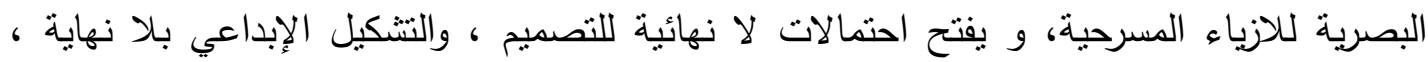
ويحصل مصمم الازياء المسرحية على أزياء مبتكرة دائماً وذلك بتغيير خطوات عملية طلى النسيج. 


\title{
The Potential of Origami Concept In the Forming of the Theatrical Costumes Design
}

\begin{abstract}
:
Origami concept is one of the biggest trends of design in the world for the past few years, Origami is not only a sophisticated art form, but it inspires innovative concepts in design and inventions in engineering, architecture, and technology. Also this art of paper folding has greatly influenced artists and designers from fashion to interior design, inspiring numerous origami style products and spaces.
\end{abstract}

The paper proposes an approach where theatrical costumes design can be developed according to the origami concept. Costumes designers can take advantages of the complex origami concept, by the use of folded fabric techniques and computer technology, where algorithms of mathematical and geometric patterns can produce new designs and forms of costumes design. This will opens up new horizons in costumes design inspired from origami concept in the formation of the theatrical costumes design.

Designers can set up their costumes design inspired from geometric patterns, fold, and creases, especially in the futuristic, fantasy, abstract and alien performances. This will enhance the visual visions of costumes designers, and will allow endless possibilities and an infinity creative formation. By changing the steps in the folding process, the costume designer will end up with a totally different costumes design. 